\title{
Productivity slowdown and loss of allocative efficiency: A French disease?
}

\author{
Comment on the article "Stagnation of productivity in France: A legacy from the crisis \\ or a structural slowdown?” by Gilbert Cette, Simon Corde and Rémy Lecat.
}

\section{Flora Bellone*}

\begin{abstract}
The article by Cette, Corde and Lecat presented in this special issue brings new stylised facts and a rich and fruitful discussion on the causes of the slowdown of productivity growth observed in France over the last decade. The facts established are solid. They back up the hypothesis that this slowdown is not a cyclical phenomenon, linked to the crisis of 2008, but is a structural phenomenon whose causes remain difficult to pin down. The authors put forward as a possible explanation the difficulties in reallocating resources between companies, linked notably to rigidities on labour markets and to regulations on goods markets. This comment aims to explain why the facts highlighted by Cette, Corte and Lecat are not sufficient to exclude other, alternative explanations which bring, in a more direct way, the shocks of globalisation and digitalisation into play. It draws conclusions from them in the perspective of future lines of research and recommendations of economic policy, in particular keeping aggregate productivity, not productivity at the frontier, as a target of policy action, and also considering, for each action, the risk of impoverishing reallocations.
\end{abstract}

JEL Classification: O47, F60, D61

Keywords: aggregate productivity, firms productivity, allocative efficiency, globalisation

Reminder:

The opinions and analyses in this article

are those of the author(s) and do not

necessarily reflect

their institution's

or Insee's views
*University of Côte d'Azur, GREDEG and OFCE-Sciences Po (flora.bellone@gredeg.cnrs.fr).

Received on Septembre $4^{\text {th }}, 2017$

Translated from « Ralentissement de la productivité et perte d'efficacité dans l'allocation des ressources : un mal français ? »

https://doi.org/10.24187/ecostat.2017.494t.1917 
The article by Cette, Corde and Lecat addresses the difficult issue of the causes of the slowdown of productivity growth in France. To fully understand these causes, a correct and precise diagnostic still needs to be made. This is what the article aims to do by shedding a welcome light on two open questions: Firstly, to what extent is the slowdown of productivity growth in France linked to the crisis of 2008? Then, is this slowdown observed in every firm based in France or only in certain firms, or to a more aggregated level for all or some business sectors?

The article also presents a review of the alternative explanations of this downturn that can be found in the literature: the slowdown of technological progress, the phenomenon of divergence of productivity between companies linked to the unequal dissemination of digital technologies and/or to winner takes all phenomena associated with new technologies, the deterioration of the efficiency of resources allocation due to new rigidities on product markets and/or factor markets... The article attempts to distinguish between these different explanations and seems to take the side of one cause in particular: the worsening of the difficulties of resource allocation in France since the turn of the 2000s due to rigidities, notably on the labour market and the product markets. As a consequence of this diagnostic, the article pleads the case for ambitious structural reforms in order to facilitate the reallocations of resources towards the most productive sectors and firms in France.

The present comment begins with a summary of the main stylised facts established for France by Cette, Corde and Lecat. These facts are judged to be robust and don't really suffer criticism, the authors being experts and well aware of the inherent limits to the estimations of productivity on the macro or microeconomic data that they use. Where this comment departs from the conclusions drawn in the article is on the interpretation of the facts established and on the recommendations of economic policy made by the authors. Finally, as a conclusion, we discuss the possible complementary works that might be conducted in order to be able to more robustly identify any French specificities in the current dynamics of productivity and resource reallocation observable in the global economy.

\section{The study by Cette, Corde and Lecat (2017)}

The article by Cette, Corde and Lecat presents stylised facts on the dynamics of productivity in France over the long period, with particular attention to the breaks in trends that occurred over the recent period, from 2000 to 2014. These facts are established drawing on macroeconomic data, from Insee's national accounts, over the period 1976-2014, and microeconomic data, taken from the Banque de France's database Fiben (Fichier bancaire des entreprises - a file on banking companies) over the period 1989-2014.

The main stylised fact highlighted in this article is a significant slowdown of French firm's aggregate productivity growth and median productivity, not only from 2008 onwards but also since the start of the 2000s. This downturn therefore precedes the crisis of 2008 and appears as a structural phenomenon over the recent period. This stylised fact established for France goes in the same way as what is observed for other advanced economies over the same period. ${ }^{1}$ Still in accordance with the facts established for other large economies, Cette, Corde and Lecat show that the slowdown affects all the categories of firm size and all the large business sectors of manufacturing and market services.

In relation to this literature, it is the way in which the microeconomic data are used, that we find particularly interesting because it introduces some simple but important methodological contributions, such as for example the systematic use of median values, rather than average values which are much more sensitive to outliers, for the measures of productivity based on company data. Likewise, the care given to data cleaning procedures is noteworthy. Finally, this study is the first, to our knowledge, to track, drawing on administrative microeconomic data, the distribution of the productivity of individual firms in France over such a long period, covering the crisis of 2008. This consistency in the series is one of the advantages of the Fiben base collated by Banque de France.

Beyond this general stylised fact, Cette, Corde and Lecat establish three other facts on which they base their critical analysis of the possible causes of the slowdown of productivity growth in France. These three additional stylised facts are as follows: first of all, the firms at the productivity frontier in France did not see a shift in

1. See Byrne, Fernald \& Reinsdorf (2016); Gordon (2016); Syverson (2016) for the US, OECD (2015) and Cette et al. (2016) for other industrialised countries, mainly European. 
productivity growth in the 2000 s; then, the pattern of convergence of follower firms towards this frontier did not decline over the decade of 2000; finally, the dispersion of companies' productivity levels grew strongly in France over this same decade.

For Cette, Corde and Lecat, the first two facts argue against the technological explanations for the phenomenon. According to them, the stability of productivity growth at the frontier shows that the rhythm of technological progress did not change course in France. Moreover, the maintained dynamic of convergence of follower firms towards this frontier excludes the hypothesis of a phenomenon of polarisation. However, the increased dispersion of firms' productivity levels appears to them to be perfectly compatible with the hypothesis of a deterioration of the efficiency of resource allocation in France. Throughout this comment we will review, one by one, each of these results in order to evaluate their robustness, especially against possible alternative interpretations.

\section{How should the dynamic of companies at the frontier be interpreted?}

In their article, Cette, Corde and Lecat, the productivity frontier as the median value of the $5 \%$ most productive companies each year. It is this value that increases at a growing rate over the period, therefore not demonstrating the characteristic downturn of the median value of productivity for the full set of French firms. The question asked is whether this productivity frontier trend can indeed be interpreted as a proxy of the rhythm of technological progress in France. Our response to this question is much more circumspect than the affirmative one proposed in the study.

Firstly, it must be noted that this stylised fact is not robust to a change of the definition of the productivity frontier. An alternative way of defining the productivity frontier is in fact to consider a consistent group of firms having the highest level of productivity at a given date or over a given period, and then follow this consistent group of firms' trend. But, when Cette, Corde and Lecat carry out this exercise, they find that productivity growth notably slowed down for these companies over the same decade.

To explain this paradox, Cette, Corde and Lecat highlight the weak persistence of the firms that make up the frontier, with these firms remaining at the frontier for three years on average. This weak persistence is also a trait which appears in the previous study by Andrews et al $(2015)^{2}$ : based on the OECD ORBIS international company data over the period 2001-2009, that less than $15 \%$ of the firms identified as being at the frontier in a given year stay there for 4 years thereafter. How can this weak persistence of companies at the frontier be explained? ? $^{3}$ Does it reveal a change of technological regime implying more frequent changes of leadership? Or is it the sign of a weaker link between firms' productivity and their level of technology in the current era? One reason why the link between productivity and technology might have weakened over the recent period is that globalisation creates new opportunities for productivity gains but only for the companies able to join global business chains to their advantage.

So, the frontier firms could be firms which benefit not only (or not necessarily) from the best technologies but also (or rather) better industrial organisation opportunities, having a positive impact on their ability to find skilled workers or to source the most appropriate inputs or intermediary tasks. On a more sombre note, these high levels of productivity could also reveal better opportunities of access to less competitive markets, even opportunities to avoid corporation tax, labour legislation or environmental legislation in a situation where countries are in competition. ${ }^{4}$ It is therefore important to further explore the hypothesis that the gains in productivity, which underpinned the dynamic of acceleration of the productivity frontier in France in the 2000s, were linked to company restructurings which engendered temporary gains rather than to technological progress which engendered more sustainable long-term gains.

\footnotetext{
2. The study by Andrews et al. (2015) proposes the same type of empirical exercises as Cette, Corde and Lecat. It is conducted on international data taken from the ORBIS database of the Bureau Van Dijk, reprocessed by the OECD. Regarding the Fiben data, the OECD ORBIS data have the advantage of covering 23 OECD countries in a harmonised manner. They nevertheless have a certain number of disadvantages, such as the least reliable accounting information reported.

3. This fact contrasts with the stylised facts on the heterogeneity of companies initially established at the beginning of the 1990s In particular, Baily et al. (1992) revealed the strong persistence of companies' productivity on the longitudinal data from the Census Bureau covering the decades of 1970 and 1980 . They showed in particular that about $50 \%$ of the American establishments in the first quintile of productivity still appeared in this quintile 5 years later.

4. It should be noted that the companies belonging to the frontier have a higher probability of being multinationals (Andrew et al., 2015). On the importance of industrial restructurings in the dynamics of productivity of the large groups and the complexity of the links between the productivity of these groups and the wealth of the countries, see Baldwin (2016) and OECD (2017).
} 


\section{How should the absence of divergence of follower firms be interpreted?}

Cette, Corde and Lecat also explore the hypothesis of a divergence between low productivity firms and frontier firms in France but, this time, contrary to the study by Andrews et al (2015), they do not find, with the Fiben data, any support for this hypothesis over the recent period. Conversely, they find that the pattern of convergence of follower firms at the 5\% frontier that did not slow down over the decade of 2000 .

This result of convergence is difficult to interpret. Firstly, it seems counter-intuitive in that the overall downturn of productivity growth, on the one hand, and the acceleration of this same growth for firms at the frontier, on the other hand, should rather bring about divergence. Must we conclude that the slowdown of productivity growth was more pronounced for firms in the middle of the distribution than for those at the bottom of it? If this is the case, and if we also consider the high volatility of the firms at the frontier, is it then pertinent to interpret this result of convergence as a phenomenon of technological dissemination from leading firms towards followers? In all cases, the latest works conducted on the OECD ORBIS data rather back up the hypothesis of a polarisation of the distribution of productivity (and wages) between the most productive firms and the least productive firms in OECD countries (Berlingieri et al., 2017). Interestingly, this study also shows that sectoral indicators of the degree of international openness and of the degree of intensity in the use of digital technologies are positively correlated with this phenomenon of divergence.

\section{How should the increased dispersion of productivity levels be interpreted?}

An important stylised fact in Cette, Corde and Lecat's study is the observation of an increased dispersion of firms' productivity levels over the decade of 2000 . This observation underpins the argument that the difficulties in allocating resources are an important cause of the slowdown of productivity growth in France. So, the study shows an increase of the interquartile and inter-decile dispersions of French companies' productivity distributions, which is very clear from 2000 to 2014 and increases over the last few years It is then argued that this observation is compatible with the hypothesis of a deterioration in the efficiency of resources allocation in France, over the same period.

Several questions nevertheless are worth being asked: firstly, to what extent can the dispersion of productivity be considered as a reliable indicator of allocative inefficiency? Then, to what extent can this trend be considered as a specifically French problem? Finally, what could be the causes of a recent deterioration of allocative efficiency in France?

The interpretation of the dispersion of firms' productivity levels as an indicator of economic efficiency may refer back to the framework of a general equilibrium model with heterogeneous companies and market distorsions (see in particular the Hsieh and Klenow's reference model, 2009). ${ }^{5}$ If, however, we consider a richer theoretical framework, including technological shocks and/or shocks of international openness, the dispersion of productivity will be co-determined by these factors. In other words, in a world where globalisation and digitalisation are two serious candidates for the explanation of diverging trends of productivity levels between firms, it would be useful to explore the hypothesis of a deterioration of allocative efficiency due to market distorsions by controlling also the influence of these factors.

An alternative method to that of Hsieh and Klenow (2009) to quantify allocative inefficiency consists in mobilising decomposition techniques of productivity growth, following the work of Olley and Pakes (1996) or its dynamic extensions. ${ }^{6}$ Applied on internationally comparable micro data, these methods allow the identification of gaps in allocative efficiency between industrialised countries. For example, Bartelsman et al. (2013) propose this type of analyses, on harmonised micro level data sets, in 5 countries including France and the US, over the period 1993 to $2001 .^{7}$ They show that Olley and Pakes's covariance term, which measures the link between firms' productivity and market share, is twice as high in the United

\footnotetext{
5. An illustrative model of this type is that of Hsieh and Klenow (2009) which serves as a reference in this literature. But, when it is applied to France, this model does not establish any substantial difference of allocative efficiency between this country and the US, with the two countries exhibiting very similar productivity dispersion values (Bellone \& Mallen-Pisano, 2013).

6. See in particular Melitz and Povanec (2015).

7. For France, the data mobilised are Insee's data.
} 
States than in France. ${ }^{8}$ A study by Andrews and Cingano (2014) backs up this result on the OECD ORBIS data but nevertheless shows that France's degree of allocative efficiency remains much higher than the European average, and, notably, than that of the UK.

One of the most recent works, in line with this, is that of Decker et al. (2017) who shows that the loss of allocative efficiency also accounts for a large part of the decline of productivity growth in the US over the decade of 2000. For the authors, this decline reflects, above all, weak entrepreneurial dynamism. If we refer to this study, the deceleration of allocative efficiency might therefore not be a specifically French problem but a problem that might also be affecting economies with much more liberalised markets.

Finally, with regards to the causes of this allocative inefficiency, exploratory works are, for the moment, struggling to shed light on any pre-eminent factor. For example, the study by Andrews and Cingano (2014) based on the OECD ORBIS data show the levels of employment protection and product market regulation to be one of the causes of the differences in allocative efficiency between countries. But, as Cette, Corde and Lecat accurately point out, other studies further plead the case for the hypothesis of a deterioration of the allocation of capital. For example, Gamberoni et al. (2016), working on the CompNet microeconomic database of the European Central Bank, defend this hypothesis for European economies. ${ }^{9}$

\section{The challenges in evaluating countries' "allocative efficiency" and issues of economic policy}

In conclusion, the article by Cette, Corde and Lecat points out, with new stylised facts, the difficulties in resource allocation that could underpin the slowdown of productivity growth

8. According to Olley and Pakes's method (1996), a high covariance term conveys the fact that the most productive companies exhibit relatively large market shares, which demonstrates an efficient functioning of markets. These values are respectively 0.24 for France and 0.51 for the US. Interestingly, it should be noted that on the data mobilised by Bartelsman et al. (2013), the intra-industry dispersion of productivity is weaker in France than in the US (the standard deviation there is 0.22 against 0.38 for the US). This reveals, again, the limits of simple measures of dispersion in comparing countries' allocative efficiency.

9. See also the commentary on these results by Benoit Cœuré in his allocution entitled "Convergence matters for monetary policy" for the opening of the conference "Innovation, firm size, productivity and imbalances in the age of de-globalization" of the CompNet network which was held in Brussels on 30 June 2017 (available on the Europa site of the European Commission). observed in France. This emphasis on structural change is welcome as it enlarges a debate that until now mainly confronted arguments relating to technology with arguments relating to measurement errors. ${ }^{10}$

Nevertheless, much work remains to be accomplished to both quantify the effects of allocative inefficiency and to understand its causes. Regarding quantification, international and inter-temporal comparisons must be expanded, but they raise many challenges concerning the comparability of microeconomic databases and the reliability of the methods. ${ }^{11}$ Beyond these challenges, one may also wonder whether these works focus too much on issues of intra-sectoral allocations, and not enough on problems of inter-sectoral allocations. For example, MacMillan and Rodrik (2011) and Rodrik (2013) evoke a paradox in the dynamic of aggregate productivity of less advanced countries. While they all saw very high gains in productivity in each of their manufacturing sectors over the last 25 years, only a small number of these countries saw aggregate productivity grow substantially. They explain this paradox by the fact that the share of the manufacturing industry in these countries tended to decline despite the gains in productivity. Put otherwise in these countries, the sectors which see the greatest gains in productivity are, paradoxically, not those which attract the most employment. Such risks of "impoverishing" employment reallocations are to be considered in advanced economies too, to the extent that the jobs released from firms suffering a loss of competitiveness might not be automatically reallocated towards high value added companies in the same sector but instead towards lower value added firms in other sectors.

Then, with regards to research on the causes of the inefficiency, the reasons why the allocation of labor, or of capital, might have become more inefficient in France over the recent period should be discussed further. Why might these difficulties have gotten worse over the decade of 2000? And in particular, to what extent might they be truly specific to France, while we observe a similar trend in the United States?

10. See Aghion et al. (2017) for a recent contribution to this debate. 11. To cite another example, Nishida et al. (2017) draw on a method developed by Petrin and Levinsohn (2012) in order to show that the reallocations of resources, and therefore the gains in terms of allocative efficiency, have greatly contributed to the aggregate productivity growth of a country like India while the traditional analyses, like those of Olley and Pakes, attribute the basis of aggregate productivity growth in this country to an effect of growth within companies. 
Finally, one last line of research might aim to further explore the role of globalisation in the dynamics of productivity and of resource reallocation, observable in France and the other industrialised countries (Bellone \& Chiappini, 2016). While the slowdown of productivity growth in these nations, or the dynamics of divergence between the most productive and the least productive firms are, at least in part, linked to the globalisation shock, it is to be feared that structural reforms alone only have a tiny impact on France's ability to escape this slowdown dynamic or to limit these phenomena of divergence.

In terms of economic policy, our analysis, like that of Cette, Corde and Lecat, leads to the recommendation of policy actions that aim to promote structural change in France. Two points of difference may nevertheless exist between our approach and what the authors might support. The first point of difference relates to the idea that productivity gains made by firms at the frontier could easily be disseminated to the whole economy, on the condition only that certain market rigidities be lifted. While, like the hypothesis we have made in our comment regarding them, these gains do not reflect (or not only) technological progress but rather (or also) industrial restructurings of companies which have taken advantage of globalisation, it is much less obvious that these gains are able to be disseminated to the whole economy. We believe, in all cases, that it is important that the government keeps aggregate productivity as the target in order to evaluate the benefits of its actions, without being tempted to substitute it for productivity at the frontier, since the dynamic of this frontier is not necessarily representative of growth potential for the country as a whole.

A second point of difference might concern the timing of actions. For our part, we recommend that the government first sets its priorities in terms of industrial strategies, including its choices under constraints in matters of ecological transition and international competitiveness, and then proceeds with its structural reforms with the aim of orientating the resources, capital and labour, towards the sectors and firms that meet these priorities. This vision of structural reforms is a pragmatic vision, far from a liberal vision whereby flexibility and free enterprise would alone be capable of leading France to revive a dynamic of strong and inclusive growth. In the current state of our open economies, such a laissez-faire policy might risk leading to more divergent trends rather than to the convergence hoped for. 


\section{BIBLIOGRAPHY}

Aghion, P., Bergeaud, A., Boppart, T., Klenow, P. \& Li, H. (2017). Missing Growth from Creative Destruction. Federal Reserve Bank of San Francisco, Working Paper $\mathrm{N}^{\circ}$ 2017-04.

Andrews, D., Criscuolo, C. \& Gal, P. N. (2015). Frontier Firms, Technology Diffusion and Public Policy: Micro Evidence from OECD Countries. OECD, Productivity Working Papers $\mathrm{N}^{\circ} 2$.

Baily, M., Hulten, C. \& Campbell D. (1992). Productivity dynamics in manufacturing plants. Brookings Papers on Economic Activity: Microeconomics, 1, 187-267.

Baldwin, R. (2016). The great convergence: information technology and the new globalization. Cambridge, Harward University Press.

Bellone, F. \& Chiappini, R. (2016). La compétitivité des pays. Paris: La Découverte, collection Repères.

Bellone, F. \& Mallen-Pisano, J. (2013). Is Misallocation Higher in France than in the United States? Université Nice Sophia Antipolis, GREDEG Working Papers $\mathrm{N}^{\circ} 2013-38$.

Berlingieri, G., Blanchenay, P. \& Criscuolo, C. (2017). The Great Divergence(s). Center for Economic Performance, CEP Discussion Paper $\mathrm{N}^{\circ} 1488$.

Byrne, D. M., Fernald, J. G. \& Reinsdorf, M. B. (2016). Does the United States Have a Productivity Slowdown or a Measurement Problem? Brookings Papers on Economic Activity.

Cette, G., Fernald, J. \& Mojon, B. (2016). The pre-Great Recession slowdown in productivity. European Economic Review, 88(C), 3-20.

Decker, R., Haltiwanger, J., Jarmin, R. \& Miranda, J. (2017). Declining Dynamism, Allocative Efficiency, and the Productivity Slowdown. American Economic Review, 107(5), 322-26.

Gamberoni, E., Giordano, C. \& López-Garcia, P. (2016). Capital and labour (mis)allocation in the euro area: some stylized facts and determinants $E C B$ Working Paper N ${ }^{\circ} 1981$.
Gordon, R. (2016). The Rise and Fall of American Growth. Princeton University Press.

Hsieh, C. \& Klenow, P. (2009). Misallocation and manufacturing TFP in China and India. Quaterly Journal of Economics, 124 (4), 1403-1447.

Macmillan, M. \& Rodrik, D. (2011). Globalization, structural change and economic growth. In: Bachetta M. \& Jansen M. (dir.). Making Globalization Socially Sustainable, International Labor Organization and World Trade Organization, Genève.

Melitz, M. J. \& Polanec, S. (2015). Dynamic Olley-Pakes productivity decomposition with entry and exit. The RAND Journal of Economics, 46(2), $362-375$.

OECD (2015). The Future of Productivity. Organization of Economic Cooperation and Development, Paris.

OECD (2017). Making globalisation work: Better lives for all. Organization of Economic Cooperation and Development OECD Key Issues Paper.

Petrin, A. \& Levinsohn, J. (2012). Measuring Aggregate Productivity Growth Using Plant-Level Data. RAND Journal of Economics, 43(4), 705-725.

Olley, G. S. \& Pakes, A. (1996). The Dynamics of Productivity in the Telecommunications Equipment Industry. Econometrica, 64(6), 12-63.

Rodrik, D. (2013). Unconditional convergence in manufacturing. Quarterly Journal of Economics, 128(1), 165-204.

Nishida, M., Petrin, A., Rotemberg, M. \& White T. K. (2017). Are We Undercounting Reallocation's Contribution to Growth? U.S. Census Bureau, Center for Economic Studies Discussion Papers N ${ }^{\circ} 13$ 55R.

Syverson, C. (2016). Challenges to Mismeasurement Explanations for the U.S. Productivity Slowdown. National Bureau of Economic Research, Working Paper $\mathrm{N}^{\circ} 21974$. 
